\title{
Assessment of Damage, Infestation Level and Susceptibility of Mango Cultivars to the Fruit Flies Infestation in Shendi Area, Sudan
}

\author{
Amani M. Khair ${ }^{1}$, Faiza M. A. Magid ${ }^{2}$ and Eltigani E. Ali $^{3}$ \\ 1. Department of Zoology, Faculty of Science and Technology, University of Shendi, Sudan \\ 2. Department of Crop Pests and Plant Health, Faculty of Agriculture University of Bahri, Sudan \\ 3. Department of Crop Protection, Faculty of Agriculture, University of Khartoum, Sudan
}

\begin{abstract}
Fruit flies are serious pests of Mango in Sudan; they cause substantial damage to Mango production, both qualitatively and quantitatively. This study is an effort to establish information about the pest and, to test the susceptibility of some Mango cultivars (Baladi, Kitchener, Shendi, Alphons, Abu Samaka and Bit abusamaka) to the pest infestation. A survey was carried out at Shendi area, River Nile State, during the period of May 2007 to July 2008, using a home made trap resemble lynfield traps with attractants (Methyl eugenol, Trimedlure, cue lure and Nu lure) to identify the fruit flies species found in the area and to study the seasonal abundance of the pest species and to determine the infestation percentage of different Mango cultivars. Results indicated that the fruit fly Bactrocera invadens is present all year-round in the study area, with population peak July to September. The study showed that Guava ( Psedium guajava ) represents the best alternative host for the pest. Abu samaka and Bit Abusa amaka mango cultivars were the most susceptible, with 100\% infestation, followed by Shendi 70\%, Kitchener 54\%., Alphons and Baladi (30\%, 28\%, respectively) were the least susceptible. Also results revealed that females of both species Ceratitis cosyra and Bactrocera invadens out numbered males 4-5 times.
\end{abstract}

Key words: Fruit flies, infestation, mango cultivar.

\section{Introduction}

Fruit flies of the family Tephritidae (Trypetidae) are destructive pests of wide range of fruit and vegetable crops throughout the world. In Sudan, there is an increase in the size of the production of fruits and vegetables as a result of gaining more importance as export crops and for local consumption. However, their production is seriously affected by a number of insect pests. Fruit flies are among the major pests that cause their damage. Gubara and Abu Elgasim (2004) reported that the percentage of damage due to fruit flies infestation reached $85-90 \%$ on mango in River Nile State.

Recently; in the year 2007, fruit flies were added to

Corresponding author: Amani M. Khair, Ph.D., research field: fruit fly control and fruit flies management. E-mail: amaniomda@hotmail.com. the list of the national pests of the country.

\section{Materials and Methods}

Field observations were conducted in an experimental site, namely Sendi, located in the River Nile State, Sudan. This area was selected for investigation because of heavy infestation of fruit flies. Also it was selected for the availability of all host plants (Guava, Citruses and Mangoes) and for the overlapping of fruit harvesting season, which is a favorable condition for the development of fruit flies.

The study was conducted during the period of May 2009 to July 2010 in five neighboring orchards with an area of 9-15 Feddan (one feddan $=0.42$ hectares). Each orchard was provided with 5 traps of methyl eugenol, trimedlure, cue lure and nulure distributed randomly in the orchard, (each orchard was 
considered as a replicate). Every 10 days the trap contents were collected. Identification and counting of the flies were done in the laboratory.

To determine the different species of fruit flies found in the area and their host range different sites within the area were chosen to maximize the diversity of the possible host plant species. Fruit samples collected from the ground and trees ripe and unripe were placed in paper bags, and transferred to the rearing room. Fruits from separate collection were placed in a medium to large insect aquarium according to fruit size with moistened sterile sand at the bottom as pupation site.

Pupae were collected from the sand by sieving and hold in Petri dishes lined with moistened filter papers and the Petri dishes containing pupae were placed in a rearing cage until adult emergence. Emerging flies were provided with diet (one part yeast and four part sugar) and water, till attained full body coloration for identification.

For determination of the level and degree of infestation of Mango varieties, ten trees were selected randomly from all tested cultivars Baladi and Kitchener, (early season mature cultivars) Shendi and Alphons, (mid season mature cultivars) Abusamaka and Bit Abu-samaka (late season mature cultivars).

Ten fruits of the same riping stage were collected from each tree and separated into infested and non-infested by visual signs of ovipuncture made by females to determine the level of infestation.

The infested fruits were kept in the rearing room in the laboratory to detect the degree of infestation per fruit, by counting the number of larvae per fruit.

\section{Results and Discussion}

During the period of the study, May 2009 to May 2010, it appeared that the highest number of fruit flies trapped during the humid months was associated with high relative humidity and low temperature, while the lowest number was recorded during the dry summer months. The study showed that the fruit flies, $B$. invadens and C. capitata have two peaks, in August and November while Ceritities. cosyra has only one peak, in August.

The high population of $B$. invadens and ceratits spices during August is attributed to the availability of host (mango and autumn guava) and the high level of rainfall which resulted in high relative humidity and low temperature. High population of $B$. invadens and $C$.capitata during November may be attributed to availability of host (winter guava) and the moderate humidity and temperature. Ali, et al., (2008) stated that in the center of the Sudan, B. invadens was found to occur throughout the year and the species showed several population peaks. The highest peak was recorded in August while the lowest populations were noticed in April and December. The current result agreed with the finding of Ahmed, (2001), who reported that the population of C. cosyra is largely dependent on the climatic factors, viz. temperature and relative humidity, with the peak of its population reported during August. Also Deng, (1990), and Abbas, (1998) stated that the population peak of $C$. capitata was found to occur during July, August and November to January.

Fruit flies reared out from the infested fruits showed that the prevalent species were Bactrocera invadens, Ceratitis cosyra and Ceratitis capitata, Bactrocera invadens was the most dominant one (Table 1).

$B$. invadens frequently shared the same fruit with the indigenous fruit fly species, but often occurred at higher numbers. Although it was recorded and identified in Sudan recently (Drew, 2005), it seems that this species is rapidly spreading and replacing the previously existing species.

\section{Sex Ratio}

Table 2 showed that, B. invadens and C. cosyra females were always found to out number the males at least four times, while three times for $C$. capitata males. This finding was supported by Ahmed (2001) 


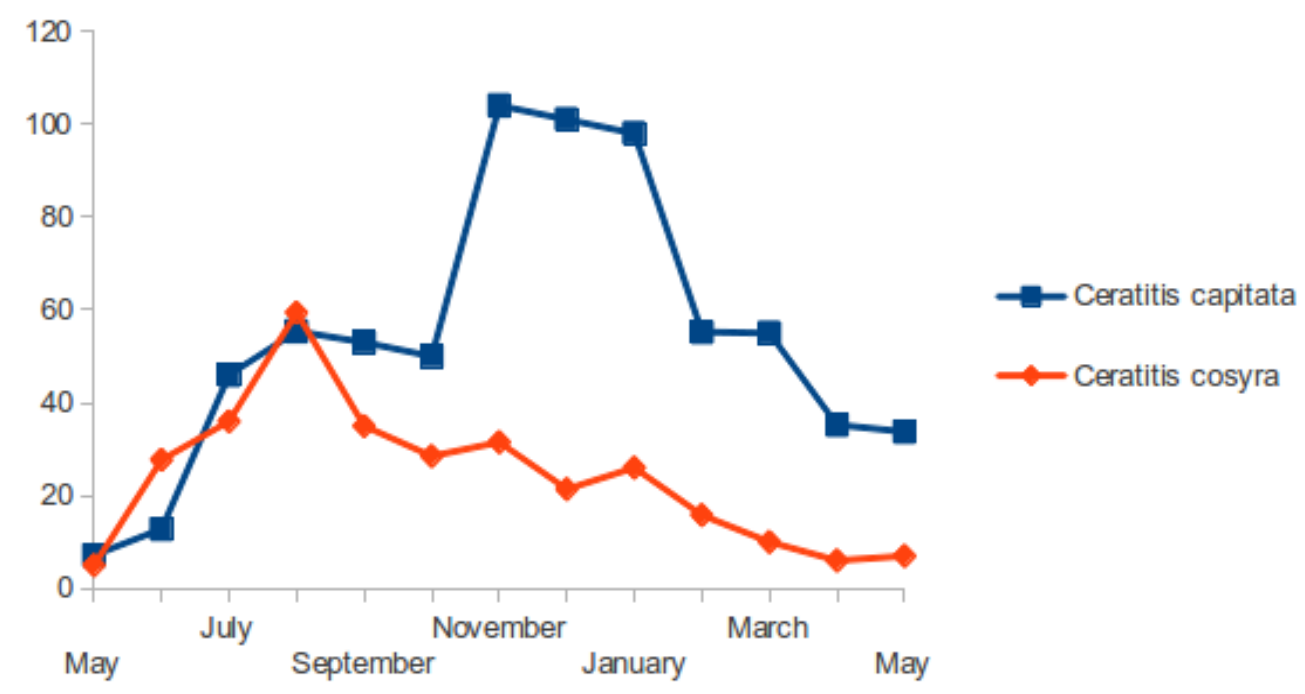

Fig. 1 Total monthly catches of fruit fly Ceratitis cosyra and Ceratitis capitata during the period May 2009 to May 2010 at Shendi area.

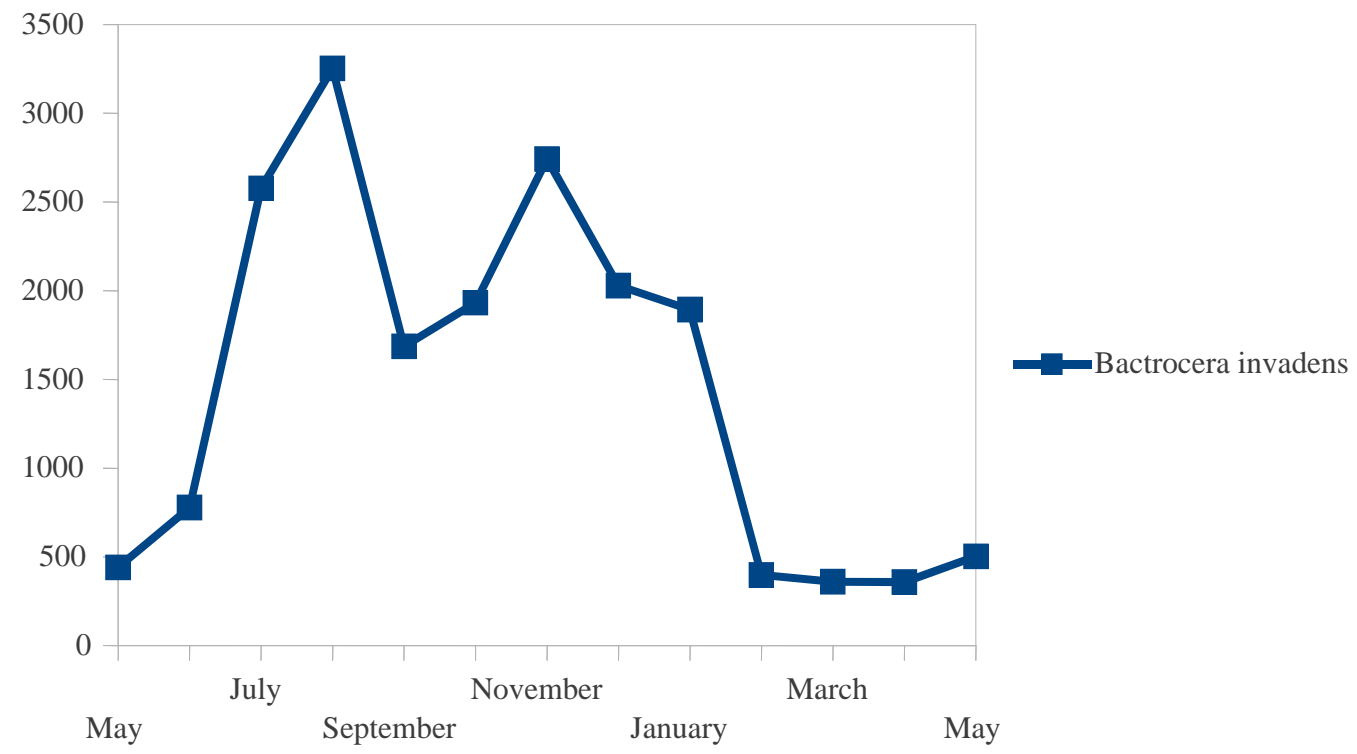

Fig. 2 Total monthly catches of fruit fly Bactrocera invadens during the period May 2009 to May 2010 at Shendi area.

Table 1 Species of fruit flies and their host range reported in Shendi area.

\begin{tabular}{ll}
\hline Species & Host range \\
\hline Bactrocera invadens & Mango, guava, orange, grapefruit, \\
& Laringa \\
Ceratitis cosyra & Mango, guava, orange, grapefruit, \\
Ceratitis capitata & Ziziphus vulgaris \\
Carpomyia incomplete & Guava, mango and orange \\
\hline
\end{tabular}


Table 2 Species percentage and sex ratio of the three fruit flies species, Bactrocera invadens, Ceratitis cosyra and Ceratitis capitata. reared in different crops.

\begin{tabular}{|c|c|c|c|c|c|c|}
\hline \multirow{2}{*}{ Insects Crops } & \multicolumn{2}{|c|}{ B. invadens } & \multicolumn{2}{|c|}{ C. cosyra } & \multicolumn{2}{|c|}{ C. capitata } \\
\hline & $\mathrm{Sp} \%$ & sex ratio & $\mathrm{Sp} \%$ & sex ratio & $\mathrm{Sp} \%$ & sex ratio \\
\hline Early mango & $61 \pm 0.6$ & $4: 1$ & $33 \pm 1.3$ & $2.7: 1$ & $0 \pm 0$ & - \\
\hline Mid- mango & $69 \pm 0.4$ & $3.6: 1$ & $14 \pm 0.96$ & $4: 1$ & $0 \pm 0$ & - \\
\hline Late mango & $71 \pm 1.7$ & $4: 1$ & $13 \pm 1.43$ & $2.6: 1$ & $3 \pm 0.6$ & $2: 1$ \\
\hline Guava & $57 \pm 2.8$ & $2.5: 1$ & $3 \pm 3.6$ & $2.6: 1$ & $28 \pm 1.5$ & $2.4: 1$ \\
\hline Citrus & $49 \pm 1.04$ & 2.3:1 & $10 \pm 3.9$ & $2.7: 1$ & 16 & $3: 1$ \\
\hline
\end{tabular}

Table 3 Level of infestation at mature and ripe stages and degree of infestation (mean \pm SE) for Mango varieties.

\begin{tabular}{llll}
\hline Mango variety & $\begin{array}{l}\text { Level of infestation } \\
\text { at mature stage }\end{array}$ & $\begin{array}{l}\text { Level of infestation } \\
\text { at ripe stage }\end{array}$ & $\begin{array}{l}\text { Degree of infestation } \\
\text { (No. of larvae/kg fruits) }\end{array}$ \\
\hline Kitchener & $48.0 \pm 18.27 \mathrm{a}$ & $52.4 \pm 2.7 \mathrm{a}$ & $67.8 \pm 19.9 \mathrm{a}$ \\
Baladi & $28.0 \pm 8.0 \mathrm{a}$ & $25.6 \pm 3.7 \mathrm{~b}$ & $26.4 \pm 11.2 \mathrm{a}$ \\
Shendi & $70 \pm 3.16 \mathrm{ab}$ & $74.2 \pm 5.0 \mathrm{c}$ & $262.4 \pm 69.1 \mathrm{~b}$ \\
Alphons & $30 \pm 7.07 \mathrm{abc}$ & $29.0 \pm 1.2 \mathrm{~b}$ & $63.2 \pm 17.0 \mathrm{a}$ \\
Abu-samaka & $82.0 \pm 9.69 \mathrm{~b}$ & $83.8 \pm 7.6 \mathrm{c}$ & $440.0 \pm 117.9 \mathrm{~b}$ \\
BitAbusamaka & $66.0 \pm 6.7 \mathrm{ab}$ & $71.2 \pm 2.5 \mathrm{c}$ & $333.8 \pm 46.8 \mathrm{~b}$ \\
Overall mean & $59.0 \pm 4.89$ & $56.00 \pm 4.5$ & $198.9 \pm 36.6$ \\
\hline
\end{tabular}

Means with the same letter(s) are not significantly different according to Duncan's Multiple Range Test.

who reported that the sex ratio of $C$. cosyra was found to be $4: 1$ and Musa (2005) reported a sex ratio of $B$. invadens, 4:1. Rendel et al. (1995) stated that the female fruit fly Ceratitis cosyra out numbered the males by five times.

The nature of damage due to fruit flies infestation (level of infestation at mature and ripe stage and degree of infestation), were recorded throughout the fruiting seasons of mango. The results in table 3 showed that during the mango fruiting season and among the varieties tested, the variety Abusamaka proved to be more susceptible to fruit flies infestation, followed by Shendi, Bit Abusamaka, Kitchener, Alphons and Baladi variety for the level of infestation at mature and ripe stage. While in the degree of infestation, Abusamaka followed by Bit Abusamaka variety, then Shendi, Kitchner, Alphons and Baladi. The results indicated that there were no significant differences between the mango varieties Shendi, Abusamaka and Bit Abusamaka, but there was a significant difference between them and the other mango varieties Kitchener, Baladi and Alphons. Baladi and Alphons proved to be the least susceptible varieties.
The mango cultivars tested indicates significant differences between level and degree of infestation. This may be due to yellow colour, strong aroma and high sugar content which might have an attractive effect on the flies. This finding was supported by Prokpy (1978) who found that the yellow fruits were the most attractive among other fruit colours.

The mango varieties, Kitchener, Shendi and Abusamaka were found to be more susceptible to fruit flies infestation while Baladi and Alphons were the least susceptible. Although Kitchener, Shendi and Abusamaka mango varieties represent different maturity periods, no significant difference was found between these varieties in their infestation level. This indicates that low number of fruit flies can cause significant damage if the preferred hosts are available. High percentage of infestation among Shendi and Abusamaka varieties may be due to the coincidental ripening stage of these varieties and the maximum population of fruit flies as a result of suitable climatic factors. These results are supported by Ahmed (2001) who reported that among the tested mango varieties, Alphons and Baladi were the least susceptible varieties while Abusamaka variety showed low 
susceptibility in the laboratory with high susceptibility in the field condition. Effect of mango variety on number of larvae per fruit (degree of infestation) showed that Shendi, Abusamaka and Bit-Abusamaka varieties were highly susceptible and there was no significant difference between them. Similar results were also reported by Ahmed (2001).

\section{Conclusions}

Monitoring of Tephritidae fruit flies in Shendi area revealed the existence of three fruit fly species, under the genus Ceratitis and Bactrocera. These are: Mango fruit fly, Ceratitis cosyra, Mediterranean fruit fly, Ceratitis capitata and Asian fruit fly, Bactrocera invadens.

Within the 6 years of invasion, Bactrocera invadens displaced Ceratitis capitata and Ceratitis cosyra and became the predominant fruit fly pest in Shendi area. This is because it is a polyphagous, short life cycle, high fecundity and high sex ratio. The study showed considerable differences in infestation level in the mango tested varieties (Kitchener, Baladi, Shendi, Alphons, Abusamaka and Bit-Abusamaka). Shendi, Abusamaka and Bit-Abusamaka were found to be more infested.

\section{References}

[1] Abbas, A. M. 1998. "Assessment of Some Cultural Practices for the Control of the Fruit Fly_Ceratitis capitata.” M. Sc. Thesis, University of Khartoum Sudan.

[2] Ali, E. E., Abbas, A. M., and Abelrhman, A. A. 2008. Cultural practices to control fruit flies National project for control of fruit flies in Sudan, Workshop 26-27\8\2008.

[3] Ahmed, E. E 2001. "Studies on Mango Fruit Fly Ceratitis Cosyra in Central Sudan.” M.Sc. Thesis, Faculty of Agriculture Science University of Gezira.

[4] Drew, R. A. I., Tsuruta, K., and White, I. M. 2005. A New Species of Pest Fruit Fly (Diptera: Tephritidae:Dacinae) from Sri Lanka and Africa African Entomology. 13 (1): 149-54.

[5] Gubara, S., and Abu Elgasim, M. 2004. Fruit flies, Plant Protection Administration, Ministry of Agriculture and Forestry. Bull., Nov. 2004.

[6] Mohd E. M. 2005. Oviposition, preference and development of the fruitfly Bactrocera spp (Diptera: Tephritidae) on Guava, Mango and orang fruit. MSc. Thesis, faculty of Agriculture Science University of Gezira.

[7] Prokpy, R. J. 1978. "Visual Responses of Apple Maggot Flies Rhagoletis Pomonella: Orchard Studies.” Entomol. Exp. App. 11: 403-22.

[8] Rendell, C. H., Mwashayengi, E., and Banga, D. E. 1995. "The Mango Fruit Fly Population and Varietal Susceptibility Studies.” The Zimbabwe Science News 29. January-March 1995. 